\title{
La primera y la última aventura de Bigas Luna: En los lindes de lo marginal
}

Carolina Sanabria

\begin{abstract}
RESUMEN
El presente artículo se propone explorar la creación audiovisual del director catalán Bigas Luna con base en su primer y su último trabajo a la fecha, distanciados en un plazo de treinta años -1976 y 2006 respectivamente- con el fin de evidenciar el salto cualitativo en su filmografía, con condiciones distintas de producción, donde su estética underground evoluciona a otra más comercial, definitivamente más consolidada.
\end{abstract}

Palabras clave: Bigas Luna - Tatuaje - Yo soy la Juani - Underground - marginal.

\begin{abstract}
The first and last adventure of Bigas Luna: In the Marginal Boundaries. The presented article intends to explore the audiovisual creation of the Catalonian director Bigas Luna based on his first and last work to date, separated over a 30 year period- 1976 and 2006 respectively- with the aim of demonstrating the qualitative leap in his filmography, with different conditions of production, where his underground esthetic evolves to another more commercial, definitely more consolidated.
\end{abstract}

Key words: Bigas Luna, Tattoo, I am the Juani, Underground, marginal.

\section{Un ensayo}

La caída de la opresión franquista en España no supuso, en modo alguno, una democratización automática en las condiciones de producción discursiva. Durante el período de transición se mantuvieron algunas constantes que caracterizaron al cine de la dictadura, como la coexistencia con las medidas que asumió el partido en el poder después de Franco,

* Filóloga. Máster en Literatura Latinoamericana. Doctora en Comunicación Audiovisual y Publicidad por la Universitat Autónoma de Barcelona. Profesora de la Escuela de Estudios Generales de la Universidad de Costa Rica. Profesora de la Maestría en Cine de la Universidad de Costa Rica. 
la Unión de Centro Democrático (UCD), en cuanto a la supresión definitiva de los códigos de censura, según Decreto Ley 3071 de 1977 se refiere. Sin embargo, no con ello terminaría el ejercicio del celo censor, como lo constata - por citar dos de los ejemplos más polémicos- el secuestro de El crimen de Cuenca (1979), de Pilar Miró, o los problemas judiciales del documental Rocio (1980), de Fernando Ruiz (Trenzado Romero, 1999: 91), de los que se obstruyó su distribución y exhibición inmediata. De la misma situación da cuenta Tatuaje. Primera aventura de Pepe Carvalho (1976), inmediata al fallecimiento del general Franco. Al igual que otras producciones del cine español de su generación, el film, de distribución escasísima y con problemas de censura, se vio circunscrito a los últimos remanentes de una política represiva, materializados en la demanda de cortes ${ }^{1}$. Años más tarde, a partir de la entrada del gobierno socialista, el control institucional en el ámbito de la enunciación discursiva desaparece paulatinamente - para ser sustituido por otros-.
El bautismo en la carrera filmográfica de Bigas Luna está dado por la literatura, a partir de una cinta basada en la novela homónima de Manuel Vázquez Montalbán (1974). Es preciso tener este dato en cuenta en lo sucesivo al explorar la relación entre textos literarios y fílmicos: se trata de materiales independientes pero complementarios, discursos heterogéneos con formas expresivas disímiles, prácticas significantes de diversa entidad (Sánchez Noriega, 2000). El propio Vázquez Montalbán colaboró en la adaptación del guión, en el que también participó el director, como ha sido habitual en su producción fílmica ${ }^{2}$. El resultado fue bastante fiel, aunque se apegara demasiado a la novela sin haber desplegado un desarrollo suficiente de la creatividad -que confirmaría lo que sostiene Sánchez Noriega: que el parámetro de fidelidad respecto al texto original no constituye en modo alguno garantía de éxito (2000: 55).

El valor de esta película reside más que todo en consistir una preparación para la producción de sus largometrajes, una forma de "aprender

1. Pedían siete, aunque sólo se suprimió una secuencia (Llinás, 15.12.1976: 28).

2. Bigas suele participar en las adaptaciones tanto de las novelas de otros autores (Almudena Grandes, Didier Decoin, Antonio Larreta, Manuel Vicent) como de sus propios relatos, algunos de los cuales han sido rodados por otros directores -como Josep Anton Salgot (Mater Amatísima, 1979-1980, a partir de un relato homónimo) y Álex de la Iglesia (Perdita Durango, 1995, basado en la novela de Barry Glifford)- o que no han sido rodados del todo. 
el oficio sin meterse en grandes complicaciones" (Weinrichter, 1992: 23), como el mismo Bigas lo ha reconocido: "Lo único que me interesa de $T a$ tuaje, mi primera experiencia larga, es que es muy digna de encuadres, los pequeños detalles están cuidados. El resto no me interesa tanto, narrativamente es muy floja" (en Sánchez, 1999: 85). Abundan fragmentos sin contraste lumínico, escenas deficientes en color, planos sin profundidad, una banda sonora pobre, acorde con el escaso presupuesto que revela la película-doce millones de pesetas, según el director, "el mínimo dinero que se necesita para hacer algo bien" (en Llinás, 15.12.76: 28)-3․ No obstante, con la natural evolución del oficio de cineasta -y su posterior institucionalización, además del apoyo presupuestario-, estos problemas no tardarían en ser subsanados. Lo importante, como sostienen Balló, Espelt y Lorente, es que a partir de esta experiencia Bigas aprendería que los mecanismos de captación del espectador no se reducen al seguimiento de la peripecia argumental, sino a una atmósfera audiovisual envolvente (1990: 294-295). Por ello Tatuaje debe ser vista como una película preliminar, como parte de una filmografía que permite descubrir desde entonces lo que Javier Memba llama el "interés inusual por la elaboración de sus imágenes de un modo personal" (en Pisano, 2001: 21).

En lo que respecta a la historia, Bigas parte de la tradición de cine policiaco durante finales de la década de los cincuenta y principios de los sesenta -con films de bajo presupuesto y producidos en Barcelona- (Gubern et alii., 1997: 274), aunque contiene rasgos que se recuperarán con posterioridad. El más evidente (el leit-motiv) es esa voluntad de transgresión -para la época: los años setenta- que se plasmaba en las epidermis de los sujetos inscritos en la marginalidad, habitualmente de contraventores o aventureros ("marinos y gente de mal vivir", según el antiguo tatuador Evaristo).

Así pues, Tatuaje se ambienta en una atmósfera underground -incluso kitsch- en las zonas populares de Barcelona y Amsterdam. Es la radiografía de un lugar en cuyos rincones se asientan los pobladores de un mundo arrabalero: tatuadores, lustradores de calzado, furcias de burdeles baratos y peluquerías con rulos, donde reina "esa gordura sin paliativos, sin liposucciones, la gordura de los pobres" (Pisano, 2001: 63). El mismo protagonista, el detective gallego

3. En interiores los personajes se suelen confundir con la escenografía por falta de iluminación adecuada, y en exteriores la luz del sol parece ser la única fuente, por lo que en la mayoría de las tomas hay ausencia de luz de relleno, de realce, de fondo y hasta de recorte. Incluso se violan reglas básicas, como cambios de planos en movimiento a planos estáticos que evidencian cortes descuidados. 
Pepe Carvalho, no es ajeno a ese entorno, como lo muestra su relación con Charo, una de las prostitutas de la zona (Fig. 1). Pero ante todo, Carvalho es un apóstata: ex agente de la CIA, ex comunista y ex intelectual -que prende fuego a los libros leídos (como "El Quijote", lo que puede parecer una irreverencia) para encender la chimenea en verano: en suma, un ex-céntrico-. Como profesional no es intachable (la novela menciona varias veces -aunque no ofrece razones- que estuvo en la cárcel): "Yo no tengo nada que ver con la policía, ni me interesa", rescata el film.

El propio Vázquez Montalbán, un enamorado del cine cuyas novelas lo han convertido en el escritor español con mayor cantidad de adaptaciones, ya había tenido en cuenta el potencial cinematográfico de este personaje, su protagonista en una veintena de relatos, y consideraba al actor francés Jean-Louis Trintignant como el prototipo idóneo para encarnar al detective (en Riambau, 31.08.1989: 34), papel que terminaron desempeñando Carlos Ballesteros en la puesta de Bigas Luna, Patxi Andión en la secuela Asesinato en el Comité Central (1982), de Vicente Aranda, y Juanjo Puigcorbé en la serie de televisión. El perfil es el de un sujeto neoepicureísta que sintoniza con las coincidencias personales del

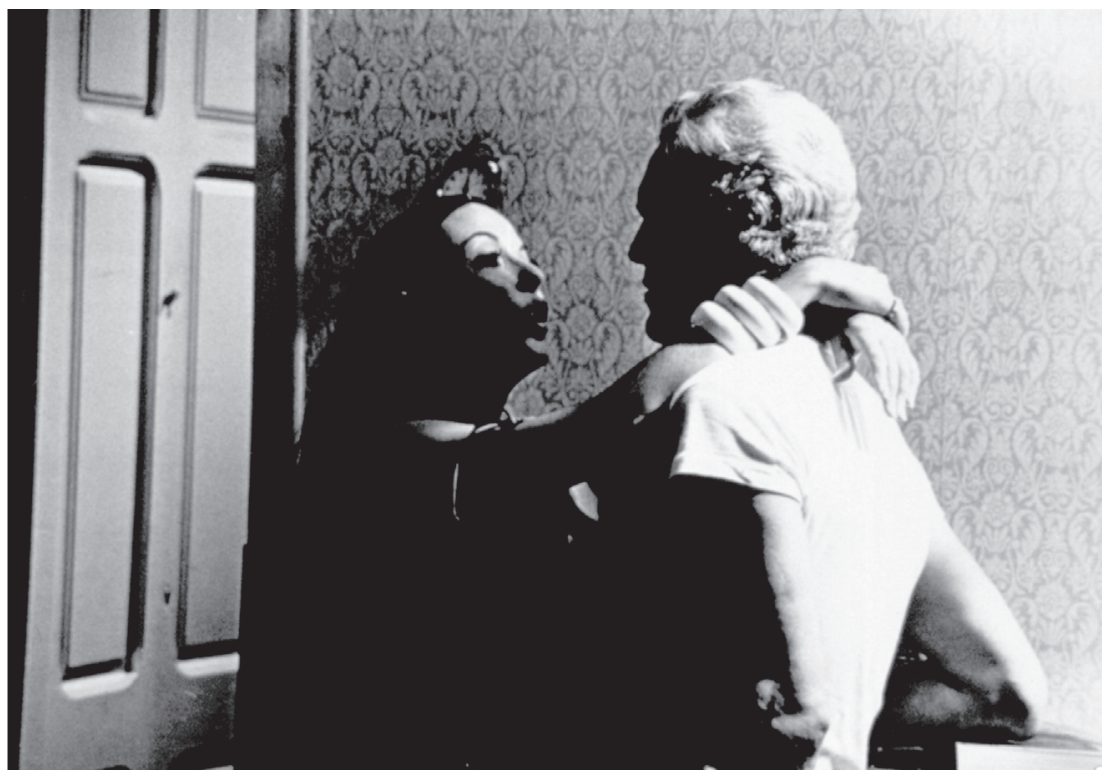

Fig. 1. Pepe Carvahlo (Carlos Ballesteros) con una de las prostitutas del Raval. 
director catalán. La predilección que éste desarrollará en su posterior filmografía empieza a hacerse patente con el protagonista de su opera pri$m a$ : el gusto por placeres efímeros -como casi todos-: las mujeres y la buena mesa. La novela tiene repetidas alusiones al placer gastronómico que retrata a Carvalho como un auténtico gourmet -acaso alter ego de Bigas-, algunas de las cuales la película destaca, como la meticulosa preparación de una cena con Charo, la comida en un restaurante con Teresa Marsé (a la que replica que "comer cualquier cosa es lo peor que se puede hacer en este mundo") o la degustación final de una paella (que al estar pasada le impide celebrar plenamente del éxito de la indagación $)^{4}$.

La historia inicia con la aparición en la playa de un cuerpo sin vida que "habría salido del mar no sólo con la desnudez de la muerte, sino también con la desnudez del anonimato más absoluto" (Vázquez Montalbán, 1997: 25). Su única seña de identidad es un tatuaje estampado en la espalda -brazo, en la cinta-cuyo provocador mensaje reza: "He venido a revolucionar el infierno". Como ocurre en el texto de Manuel Vicent más tarde adaptado también por Bigas, el hallazgo de un cuerpo en la playa da paso a un revuelo acerca de su identidad, la cual en la novela de Vázquez Montalbán es delegada por el señor Ramón, un sujeto aparentemente desvinculado, al anónimo cadáver.

La matriz mítica sobre la que se articula la historia sigue una estructura más o menos definida, la cual, aparte del arquetipo edípico -al que deben mucho los relatos policiacos-, oscila entre los dos modelos que Francis Vanoye distingue: Fausto ("la crisis, la visita del tentador, las resistencias, el otorgamiento y ejecución del contrato, el descubrimiento o la toma de conciencia de lo perverso del acuerdo, la lucha con el demonio, etc.") e Ícaro (Vanoye 1996: 42) (conforme se cumple un acercamiento al objeto de su curiosidad, el tránsito se vuelve cada vez más inaccesible y peligroso: en Holanda, Carvalho es vigilado, perseguido por la policía y golpeado por el grupo de Singel). Como novela policiaca, las circunstancias de la muerte de Julio Chesma -excedidas por el detective- son orbitales ${ }^{5}$, de

4. La propensión hacia lo culinario motivó al escritor gallego a utilizar la figura de este personaje para presentar posteriormente sus enlaces gastronómicos, colecciones de recetas, etc. tituladas "Las recetas de Carvalho" (1989) y la serie de "Carvalho gastronómico" (2002).

5. Habiéndose convertido en una obsesión personal -lo que supera el mandato inicial (la contratación de sus servicios)-, encuentra respuesta en el sujeto que lo contrató (de ahí que en Amsterdam Cavahlo comente que su círculo empieza a cerrarse, a llevarlo al final: "Al punto de partida, a Barcelona. Es la sorpresa que guardan todos los círculos”). 
donde la adaptación recupera no sólo la esencia del género sino uno de los ejes de la filmografía de Bigas Luna: la obsesividad. A través de esta figura que se mueve en los márgenes sin nadar del todo en sus aguas, Tatuaje narra una historia de persecuciones, de voyeurismos, de seguimientos e indagaciones (Fig. 2), de búsquedas obsesivas que, de una u otra forma, se reelaborarán en las producciones inmediatas, sobre todo en su siguiente largometraje, el que lo catapultaría, Bilbao (1979). Pero antes desarrollaría su obsesión en una serie de trabajos con énfasis erótico, que en su momento fueron calificados de porno.

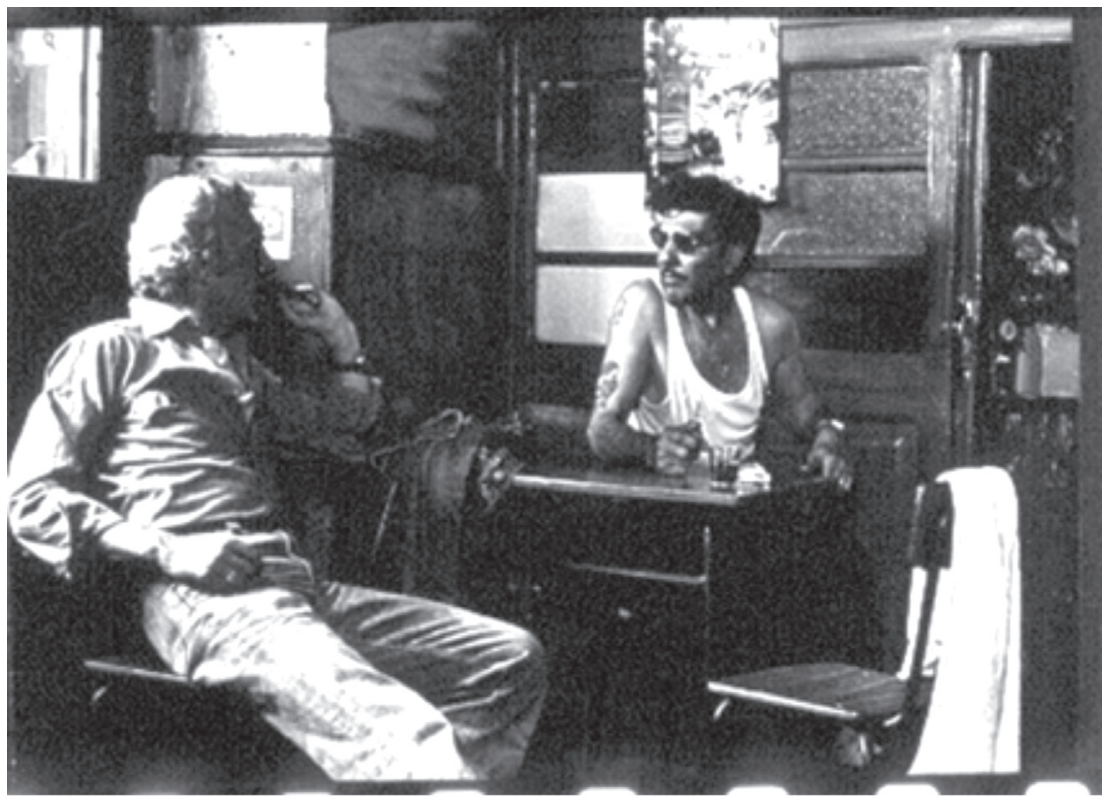

Fig. 2. Pepe Carvahlo (Carlos Ballesteros) en sus primeras indagaciones.

\section{El tránsito erótico: los vídeos porno kitsch}

Razones como el fracaso comercial de Tatuaje habrían motivado a
Bigas, siempre desde la más rotunda marginalidad, a dedicarse a la producción de un nuevo material videográfico que, de acuerdo con Román Gubern, se vendió periódicamente 
para sufragar los gastos del trabajo anterior (07.03.2002), a la vez que le permitió adquirir el dominio técnico necesario para el oficio (Balló, Espelt y Lorente, 1990: 294) y para ser catalogado como uno de los directores españoles eróticos después de la transición. En su momento, estos vídeos fueron vistos como pertenecientes al género porno, aunque hoy resultan más bien eróticos, lo que revela que las designaciones y representaciones en torno al sexo también se transforman (y se acentúan tras situaciones de replanteamiento político).

Rodados en 1976 en 16 mm, fueron más tarde comercializados en una sola compilación que llevaba por título general Historias impúdicas. De un promedio aproximado de unos 10 minutos cada uno, se trataba de once cortos de estética kitsch, entre los cuales figuran los temas del autoerotismo -bien ante un reflejo especular o ante imágenes fotográficas-, de la gastronomía o tópicos lésbicos. En realidad, se trata de una composición de escenas sin más conexiones entre sí que un proceso en general que va del cubrimiento de los cuerpos-femeninos, a excepción de El ídolo- hasta su gradual develación. En ese sentido, el interés se aboca a satisfacer la pulsión visual, pues el uso de la cámara se focaliza en la mostración de cuerpos, con énfasis en zonas erógenas antes que sexuales (a excepción de un primerísimo plano del genital masculino), sin imágenes de coitos - de ahí que la intención parezca dirigida a estimular la pulsión visual del espectador-. La única práctica propiamente sexual que se ha incluido se cierne en torno a hábitos solitarios -en $E l$ espejo, El desayuno, La millonaria y $S k i$ [sic]-, aunque, al igual que en el género pornográfico, la cámara prioriza los efectos en el rostro, pero sólo de las mujeres. En El ídolo, el único donde el varón se muestra como objeto del deseo (despojándose de su ropa, con cierta dosis de desgarbo, en una cinta que el personaje proyecta para estimular a la mujer que lo acompaña), aparece impenetrable - una suerte de antecedente del Leo de Bilbao-, inaccesible todo el tiempo: nunca se desprende de sus gafas oscuras, ni en la realidad (del acto sexual) ni en la proyección (el vídeo dentro del vídeo) -cuando se muestra desnudo ${ }^{6}$.

Cabría arriesgarse a especular con que el éxito de este material ubicado en los albores del llamado

6. No deja de ser sintomático que en la carátula de presentación del formato en vídeo las únicas dos figuras masculinas (el personaje y el propio director) luzcan, a diferencia de todas las intérpretes femeninas, gafas oscuras. 
cine del destape le permitiera a Bigas Luna resolverse por el erotismo en la provocación y trazar el camino inicial por el que encauzaría buena parte de su producción posterior.

\section{Yo soy la Juani o lo marginal que se vuelve comercial}

Treinta años después del estreno de Tatuaje y tras unos pocos años de silencio filmográfico, Bigas regresó al cine con Yo soy la Juani (2006), esta vez no una adaptación literaria, a diferencia de su opera prima, sino una historia basada en una idea personal que resultó de un ejercicio de observación de años, como lo había hecho años atrás con otro de sus personajes protagónicos, el humilde pero trepador Benito González de Huevos de oro (1993). Sin embargo, a diferencia de este sujeto que Bigas describe como inhumano e injusto - caricatura del macho ibérico-, la ambición de la Juani no la lleva a la misma actitud -como al final, que tras su decepción en la ciudad, regresa a su pueblo para ver a su padre enfermo, para volverse a lo mismo-. Bigas, así pues, despliega su capacidad de reconocimiento primero y estilización posterior de lo que consiste en un fenómeno cultural, económico y estético, delineando un personaje, como Benito, "mezcla de brutalismo ibérico y kitsch americano" (en del Pozo, 30.01.2005: 1): la Juani responde a un personaje que no se soporta básicamente en la creación imaginativa, sino que tiene una base sociológica.

A la película no sólo le interesa centrarse en el argumento y sus aspectos de ambientación como el mundo del tunning (modificación $\mathrm{u}$ ornamentación externa de los coches a gusto de sus propietarios), de los centros comerciales, del hip-hop o de las discotecas, sino rescatar una dimensión más bien, si se quiere, técnica, puesto que gira en torno a la búsqueda de experimentación de nuevos modos de enunciación visual, de contraste de colores (predominantemente oscuros y metálicos, lo que evoca la etapa oscura del director,

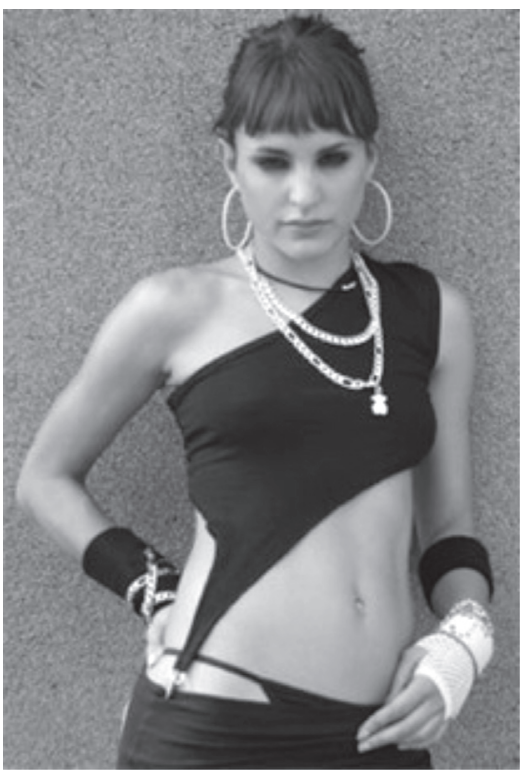

Fig. 3. La Juani (Verónica Echegui) con su moda provocativa y hortera. 
con eventuales tonos pálidos y brillantes, especialmente los derivados de los cálidos dentro de los que sobresale el rosa) y de mensajes de texto de móvil que por momentos llenan la pantalla. Yo soy la Juani es un film, pues, que reúne la antigua vocación de artista plástico del autor con su última fase de interés -el vídeo arte y la instalación-. A raíz de ello, la estética general del producto $-\mathrm{y}$ con especial énfasis la presentación inicial de créditos- tiene alta semejanza con la del montaje de los videoclips e incluso de los videojuegos -sobre todo en las carreras de coches o las de karts-. Es más, buen metraje del film transcurre como si se tratara de un videoclip musical aun cuando no contenga necesariamente la presencia de una banda sonora o un tema que lo dirija ${ }^{7}$.

La Juani es una mujer moderna y joven (Fig. 3), con rasgos de una adolescencia -en los ornamentos rosas de su habitación y de sus accesorios, el tipo de actividades típicamente lúdicas y sobre todo la expresión pueril de furia o contento- que las sociedades occidentales no ven con malos ojos que se tienda a prolongar hasta entrados los primeros años de madurez. Bigas sitúa a este personaje en un pueblo sin nombre de la península perfectamente extrapolable a los extrarradios de cualquier gran ciudad como Barcelona, Madrid o Euskadi ${ }^{8}$. Es el prototipo de chica que procede de un entorno humilde y ha de levantarse a las 7:00 para trabajar, pese a lo cual -o gracias a lo cual, según se vea- le concede mucha importancia a su círculo de amigos y con unas ganas inagotables de triunfar, aunque no por vía de la formación universitaria: algunas abandonan hasta los estudios secundarios porque -en consecuencia con la inserción definitiva de la mujer en el mercado laboral- entran a trabajar como peluqueras, dependientas o cajeras, que es el caso de la Juani. Así, cuando llega con su amiga Vane a Madrid, ni siquiera tiene vocación en seguir el consejo del agente, productor y manager Marcos Sáez: de ahí su frustración al sentir que no

7. De hecho, ha sido el único film de Bigas del cual se lanzó un cd de su banda sonora bajo el sello de Universal.

8. A partir de la difusión de este proyecto, una periodista - Lea del Pozo- le dio seguimiento a este fenómeno masivo, adelantándose con un amplio reportaje en el que profundizaba el perfil de este colectivo y se remontaba a su génesis en los años sesenta, con la inmigración de trabajadores a las grandes ciudades. Las juanis no sólo serían chicas de pueblo: también vendrían a ser las jovencísimas - escasamente mayores que las lolitas (o, si se prefiere, lulús)- descendientes de primera o segunda generación de aquel colectivo y que han emergido con la llegada del nuevo milenio. El sentido de pertenencia que han desarrollado no está ligado ni a las grandes ciudades ni a los pueblos de sus padres sino a sus propios barrios ubicados en zonas aledañas a la ciudad -razón por la cual hablan un argot propio (garrulo) con un acento distintivo- que aun así están dispuestas a abandonar, como lo hace Juani, para materializar su sueño (30.01.05: 1-3). 
comprende las clases de teatro y su escaso interés en aprender inglés, donde Bigas aprovecha para introducir una crítica vertida como lamento de la Juani: "Estoy harta de todo. En los castings ni me miran, en las clases de inglés no me entero de nada, en las de teatro nos piden que seamos zapatos que yo no sé $p a$ qué coño querrán que sea un zapato. Que yo no quiero ser un zapato, tía, yo quiero ser una actriz, ¿sabes? ¿tan difícil es de entender?" Pese a todo, nada -ni siquiera la dificultad propia del medio-mella su decisión de triunfar que sobrepone a una relación personal, la cual, por lo demás, no le venía a ofrecer un futuro que se ajustara a sus perspectivas: su novio, el Jonah ${ }^{9}$, no muestra mayor grado de compromiso, lo que también revela un elevado grado de infantilismo constatado en las mencionadas actividades de esparcimiento como las carreras de coches entre los amigos. En contraste, la seguridad o autoconfianza de la Juani se remarca en aspectos que van desde el mensaje que ella graba repetidamente en el móvil como tono para las llamadas (Viva la Juani) una vez que se marcha a Madrid, el tatuaje en el cóccix donde aparece su nombre rodeado de estrellas o bien el título del film, que apunta a una reafirmación de sí misma, a una confirmación de su individualidad y de sus metas: "Estoy creciendo", dice al final con determinación, como a modo de conclusión, "y te juro que lo voy a conseguir. Me dejaré la piel. Voy a ser actriz. Dejaré de ser una niña pero seguiré siendo la Juani".

$\mathrm{Su}$ chico, el Jonah, es un paradigma de aquellos chicos que también tienen pocos estudios y se dedican a otros oficios -son yeseros, carpinteros, albañiles o camioneros-, pero reciben ingresos suficientes para dedicarse a su devoción, en su caso el tunning. Como lo había previsto el mismo director en su página web, el Jonah es "un personaje muy divertido, choricillo, dedicado a su coche y a ligar sin que la Juani se entere. Tiene su pandilla de amigos y los centros comerciales son sus catedrales" (http://www.clubcultura.com/ clubcine/clubcineastas/bigas/soyla juani $/$ n.htm).

Tal como ocurre con la ornamentación de los coches en el caso de los varones, el signo más claro de singularidad y de definición de las juanis opera a nivel de percepción física -en consonancia con un entorno que cada vez se define más por lo visual-: cuidan de su imagen hasta la extenuación, les encanta ir de compras a cadenas

9. Por cierto que su nombre (hipocorístico de Jonathan) revela la tendencia en la nominación -cada vez más marcada- en continuar un estilo anglosajón, en contraste con el apelativo cariñoso de Juani (Juana), un nombre castizo cuyo uso ha venido declinando en las últimas décadas pero que Bigas se ha interesado en rescatar. 
de ropa atrevida y precios asequibles (preferiblemente con ofertas), visten "pantalones de chándal, tejanos campana, camisetas de tirantitos", que acompañan de accesorios como "su amuleto de la suerte y pendientes de aro grande" (http://www.clubcultura.com/clubcine/clubcineastas/bigas/soylajuani/n.htm). En efecto, se trata de un nuevo colectivo que representa una nueva forma de entender la moda, en la que ésta ya no se impone desde las pasarelas, sino que se adecua a su forma de vida, regida por sus modestas economías y los ingresos de sus oficios ${ }^{10}$, lo que supone una democratización en el vestir - con la salvedad de que se limita a sus lugares de origen, porque en Madrid la protagonista y su amiga se entusiasman con servicios y productos en comercios no necesariamente calificados económicos (como Mango, Fnac o Tous), pero lo importante es que su consumo se inscribe dentro de un proceso de liberación (Vane busca una clínica estética para colocarse implantes mamarios y Juani se hace un tatuaje que habría molestado a su padre)-. Independientemente de ello, la moda, como del Pozo afirma, "ya no es una cuestión de las clases altas. Estas mujeres de la periferia también deciden qué se lleva a cabo y marcan tendencias" (30.01.2005: 3). El estilo de este nuevo icono surge entonces a partir de una combinación de desparpajo y chulería con feminidad y glamour que se expresa no sólo en la forma de vestir sino en su carácter directo y desafiante ${ }^{11}$, que en ocasiones raya en la agresividad, rasgo del que por cierto Bigas se sirve en la escena de la carrera de coches -donde esta vez son chicas las que conducen-, indiscutible homenaje a Rebelde sin causa (Rebel Without a Cause, 1955) de Nicholas Ray-.

Al igual que Benito González, el otro icono ibérico de carácter también popular vislumbrado por Bigas, la Juani responde a un prototipo que no se soporta básicamente en la creación imaginativa. No obstante, en lo que atañe a la Juani se aprecia una diferencia considerable en lo que a la relación con el entorno se refiere y que es claramente evidente en la perspectiva de narración de la historia: mientras que con el personaje interpretado por Javier Bardem el conflicto se resuelve en la derrota de este último -puesto que es un personaje que busca, forzadamente, imponerse a sí mismo por encima de la realidad-, con la Juani no ocurre

\footnotetext{
10. Las condiciones del extrarradio exigen que haya una invención de las modas aguzando el ingenio, creando vanguardia a partir de la escasez de recursos (Sánchez 19-25/06: 16).

11. "Femeninas y sexys con sus tops de tirantes y ombligo al aire, pero dispuestas a llegar a las manos para luchar por un chico o aclarar conceptos con una colega", opina al respecto Agustina Rico (30.01.2005: 2).
} 
lo mismo porque intenta, desde el idealismo típico de una adolescencia recién dejada atrás, sobrevivir de la mejor manera, aun cuando las dificultades la sobrepasen, pero desde un respeto a los otros que la restituye a sí misma. A diferencia de los films -sobre todo los típicamente hollywoodenses- que llevan al protagonista, tras una serie de condiciones adversas, a alcanzar sus metas, la Juani ni siquiera llega a vislumbrarlas. Las imágenes finales pueden ser una ensoñación como una materialización de su sueño: el primer paso -el posado del calendario-. Parece como si el director "mira[ra] admirado sus contornos y su entorno, un mundo lleno de hombres despreciables, en donde la única afirmación de identidad posible para una chica es oscilar entre ser guerrera y ser hortera... y seguir tragando. Es un feminismo 'burro', instintivo más que concienciado" (Weinrichter 20/10/06). Bigas se ha encargado de practicar un despliegue de observación, de reconocimiento y estilización de este fenómeno cultural, económico y estético - "mezcla de brutalismo ibérico y kitsch americano" (en del Pozo, 30.01.2005: 1)-. El resultado es la propuesta de un nuevo icono ibérico identificado en esta especie de cenicienta marginal -que le lanza el zapato a su falso príncipe en dos ocasiones- y subversiva al relato, feminista e insumisa, en las antípodas del prototipo sacrificial personificado por Lola (Lola, 1985) o por "Bambola" (Bambola, 1996), dominadas por sus respectivas parejas), la cual supondrá una vuelta de tuerca más a la imagen de la mujer que ha estado presente a lo largo de su obra fílmica, esta vez y a pesar del entorno en contra, alentadora.

\section{Conclusiones}

Fruto de su taller, la idea, con su última película, era la búsqueda de experimentación de nuevas formas de narración y de exhibición, que por el tema suponía una vuelta a lo marginal como estética, aunque el cambio de posición (y de nombre, claro) le dio posibilidades de convocatoria que al principio de su carrera no gozaba, sobre todo a partir de su página web ${ }^{12}$. Si en Tatuaje la marginalidad había sido asumida como parte de una tendencia vanguardista de los años sesenta que desdeñaba las apariencias costosas e independizaba la pobreza material de la espiritual (Tyler 1973: 38), en Yo soy la Juani, Bigas recurre de nuevo a la marginalidad aunque

12. De hecho la misma preproducción estuvo marcada por un cambio en las formas tradicionales que implicaban, a su vez, una forma de promoción: el casting fue convocado mayormente mediante página web, así como la evolución de la producción. 
esta vez con distintos alcances $-\mathrm{y}$ lógicamente medios-: en el primer caso asociándose a la escasez de recursos de producción que influyen en el manejo adecuado de las técnicas, en tanto que en el último trabajo -una vez consolidada su figura en el panorama cinematográfico español con una crítica variada, halagüeña en unos casos y en otros no, así como un trabajo premiado a nivel nacional como internacional- vuelve a la marginalidad de temas y de imagen que lo caracterizó en sus inicios para construir una nueva historia, también dotada de trasfondo social, aunque esta vez de modo - como no podía ser de otra forma- artificial.

\section{Filmografía}

\section{Tatuaje. Primera aventura de Pepe Carvalho}

1976

Estreno en España: 05.06.1978

Productora:

Luna Films

Productor ejecutivo:

Ferran Amat

Dirección:

Bigas Luna

Argumento:

Manuel Vázquez Montalbán basado en su novela Tatuaje

Guión:

Manuel Vázquez Montalbán, Josep Ulloa y Bigas Luna

Diálogos adicionales:

Quim Monzó

Fotografía:

Tomàs Pladevall (color)

Montaje:

Emilio Rodríguez

Ambientación/Decoración:

Vestuario:

Ferran Amat, Bigas Luna

Montaje:

Consol Tura

Música:

Emilio Rodríguez

Sonido:

Toni Miró, Joan Albert Amargós

Joan Quilis

Principales intérpretes: Carlos Ballesteros (Pepe Carvalho), Pilar Velázquez (Teresa Marsé), Mónica Randall (Charo), Carmen Liaño (Queta), Carlos Lucena (Ramón), Luis Ciges (Bromuro), Terele Pávez (La andaluza)

Duración:

$85 \min$

Sinopsis:

Un detective privado, Pepe Carvalho, recibe un día un encargo del señor Ramón: descubrir la identidad de un misterioso cadáver hallado en una de las playas de Barcelona cuya única marca es un tatuaje. Carvalho empieza sus averiguaciones hasta conocer el nombre del sujeto y enterarse de que había trabajado en Amsterdam, adonde viaja y descubre sus vínculos con los negocios de drogas de Singel. Luego regresa a Barcelona, donde busca a otra mujer con 
la que el mismo sujeto también había tenido relaciones sexuales: la acomodada Teresa Marsé, quien le permitía usar su casa de la playa para recibir sus conquistas. Finalmente Carvalho se da cuenta de que en esta vivienda se produjo el asesinato, donde estuvieron involucrados el señor Ramón y su esposa Queta.

\section{Yo soy la Juani}

2006

Estreno en España: 20.10.2006

Producción:

Media Films, Virgili Films

Producción ejecutiva:

Bigas Luna, Luis De Val

Dirección:

Bigas Luna

Guión:

Bigas Luna, Carmen Chaves Gastaldo

Fotografía:

Vestuario:

Albert Pascual (color)

Montaje:

Ana Herce

Música:

Jaume Martí

Facto Delafé, Horta \& Petruchelli, Professor Angel Dust y Miguel

Marín

Principales intérpretes: Verónica Echegui (Juani), Dani Martín (Jonah), Laya Martí (Vane), Gorka Lasaosa (Nacho), José Chaves (padre de Juani), Mercedes Hoyos (Madre de Juani), Manuel Santiago (Raúl), Marcos Campos (Marcos), Ferran Madico (Productor Olavarria)

Duración:

$90 \min$

Sinopsis:

La protagonista, Juani Jurado, es una adolescente que vive en un barrio marginal con sus padres. Tiene problemas con ellos y con su novio, Jonah, más interesado en el tunning y en ligar con otras chicas. Juani quiere ser actriz e, intentando salir de su limitado ambiente, se va, con su amiga Vane, a Madrid a probar suerte. Tras algunos intentos en vano, regresa a su casa cuando su padre sufre un accidente y busca de nuevo a su novio, pero al darse cuenta de que la engaña de nuevo, regresa a la ciudad en pos de retomar su sueño. 


\section{Bibliografía}

Balló, Jordi; Espelt, Ramón y Lorente, Joan (1990). Cinema català 1975-1986. Barcelona: Columna.

Bigas Luna, página oficial: http://www.clubcultura.com/clubcine/clubcineastas/bigas/index.htm (diciembre 2004)

Gubern, Román (07.03.2002). Conversaciones en el despacho de la Universitat Autònoma de Barcelona.

et al. (1997). Historia del cine español. Madrid: Cátedra. Segunda edición.

Llinás, Maria Angels (15.12.1976). "Un Tatuaje con un corte solamente", en Tele/ eXprés p. 28.

Pisano, Isabel (2001). Bigas Luna: sombras de Bigas, luces de Luna. Madrid: Sociedad General de Autores y Editores.

Pozo, Lea del (30.01.05). "Las Juanis: antes muertas que sencillas", en La Vanguardia, Revista, pp. 1-3.
Riambau, Esteve (31.08.1989). "La primera aventura al cine del detectiu Pepe Carvalho", en Avui, p. 34.

Sánchez Noriega, José Luis (2000). De la literatura al cine. Barcelona: Paidós.

(2002). Historia del cine. Teoría y géneros cinematográficos, fotografia y televisión. Madrid: Alianza.

Sánchez, Sergi (2006). "Viva el extrarradio. Bigas Luna retrata el glamur de la periferia en Yo soy la Juani", El Periódico de Catalunya, Exit, 19-25:16.

Trenzado Romero, Manuel (1999). Cultura de masas y cambio político: el cine español de la transición. Madrid: Centro de Investigaciones Sociológicas.

Tyler, Parker (1973). Cine underground. Barcelona: Planeta.

Vanoye, Francis (1996). Guiones modelo y modelos de guión. Barcelona: Paidós.

Vázquez Montalbán, Manuel (1997). Tatuaje. Barcelona: Planeta.

Weinrichter, Antonio (1992). La línea del vientre. El cine de Bigas Luna. España: La Versal. 
